\title{
Ground subsidence information as a valuable layer in GIS analysis
}

\author{
Radosław Murdzek ${ }^{1}$, Hubert Malik ${ }^{1}$, and Andrzej Leśniak ${ }^{1}$ \\ ${ }^{1}$ AGH University of Science and Technology, Faculty of Geology, Geophysics and Environmental \\ Protection, Cracow, Poland
}

\begin{abstract}
Among the technologies used to improve functioning of local governments the geographic information systems (GIS) are widely used. GIS tools allow to simultaneously integrate spatial data resources, analyse them, process and use them to make strategic decisions. Nowadays GIS analysis is widely used in spatial planning or environmental protection. In these applications a number of spatial information are utilized, but rarely it is an information about environmental hazards. This paper includes information about ground subsidence that occurred in USCB mining area into GIS analysis. Monitoring of this phenomenon can be carried out using the radar differential interferometry (DInSAR) method.
\end{abstract}

Keywords: DInSAR, GIS, underground mining

\section{Introduction}

In recent years Geographic Information System (ang. GIS) has become an indispensable tool in the process of spatial data analysis. GIS currently has a very wide range of functionalities: creating, acquiring, integrating, processing, visualizing, analysing, modeling and archiving information about the Earth's surface and phenomena that occur on it. These functionalities are used to combine information placed in space and in time to better understand the studied phenomena and to support the decision-making process. GIS analysis finds practical applications in many areas, including spatial planning, creating maps of environmental hazards occurrence, choosing the optimal place for investment, infrastructure management, mining activity planning, etc. Due to the fact that the GIS analysis results are used to make key decisions, they must meet the high users requirements. It is important to use only reliable data for analysis. The more relevant and up-to-date information layers built on the actual data will be used, the more accurate the results will be. This article presents the possibility of using vertical ground deformation information as one of the input data layers in the GIS analysis. The aim of this work is to demonstrate the need of the inclusion of ground subsidence information in spatial analysis, especially for local government units. Radar data is currently available at a very low cost, and the information they provide could be crucial to make certain planning decisions. 
In Poland ground subsidence phenomenon associated with underground hard coal mining is a common problem in the Upper Silesia region. Within the Upper Silesian Coal Basin (USCB), 133 coal deposits are documented and according to the Polish Geological Institute, there were still 28 mines operating in this region in 2014 [1]. In the Environmental Protection Programme for the Silesian Voivodeship it was found that the maximum value of ground subsidence reaches even 1 meter per year [2]. Most often, these areas are heavily urbanised and the appearing deformations may be dangerous to the existing building infrastructure [7]. However, even a noticeably smaller terrain subsidence can cause mining damage. In the USCB area, this phenomenon leads, among others, to changes in hydrographic conditions, flooding, formation of marshlands, buildings, roads and other infrastructure facilities damages. Therefore, including ground subsidence information in GIS analysis performed in the Upper Silesia region will lead to improvement of decisionmaking processes.

To study vertical terrain displacements on large areas satellite radar imagery can be used $[3,4,5,6]$. The method of processing radar data to obtain vertical displacements information is Differential Interferometry SAR (DInSAR). The guidelines of the method and its case studies have been described by many authors [8,9]. DInSAR method consists of generating a differential interferogram which is an image of the phase difference between two radar images acquired at a certain time interval. The phase difference is proportional to the surface deformation that occurred in the direction of satellite line of sight (LOS). Precision of measurements obtained with this method depends on many factors, the most important of which are: wavelength of signal emitted by the SAR system, spatial and temporal resolution of the images, coherence of two SAR images. As for the DInSAR method it is assessed that the average precision of the vertical displacement measurements reaches $1 \mathrm{~cm}[10]$.

\section{Characteristics of used data}

The presented ground subsidence analysis was carried out in the Upper Silesian Coal Basin area. Analysed area covers approximately $2600 \mathrm{~km}^{2}$ and it was chosen because of the exploitation of hard coal conducted there on a large scale. Underground coal mining leads to the formation of many subsidence troughs of different range and depth.

In this work, the analysis of vertical surface displacements has been carried out using DInSAR method. For this purpose, two radar images acquired by the Sentinel-1A satellite (C band SAR - 5.405 GHz) at 29.11.2015 and 23.12.2015 were used. Radar images were acquired in Interferometric Wide Swath mode [11].

Radar images were used to obtain a differential interferogram representing the surface deformations that occurred between 29.11.2015 and 23.12.2015. The main parameter that can be used to estimate the quality of the interferogram is coherence. Coherence is determined by the degree of compliance of the SAR signals phase - the higher the value, the more accurate the interpretation of the interferogram will be. In the case of low coherence, interpretation is practically impossible [12]. Fig.1 shows coherent areas (areas where coherence value is greater than 0,3 ). The average coherence value of used images is 0.36 . High coherence values occur in urban and agricultural areas - especially central part of GZW where there are large urban agglomerations. On the other side, low coherence values can be observed on vegetation areas and lakes. Performing DInSAR analysis for such areas is highly limited. 


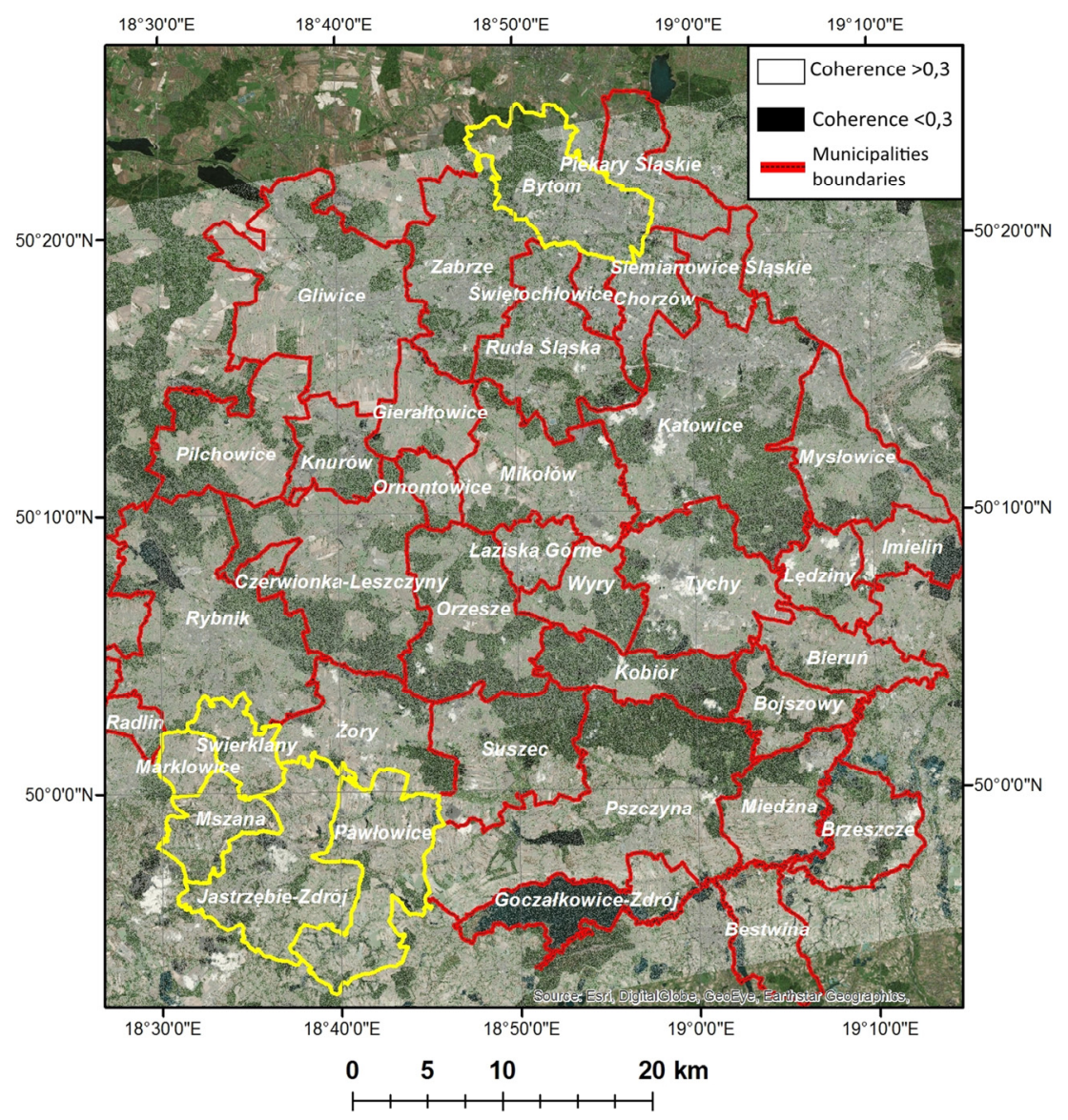

Fig.1. Map of coherent areas overlayed on orthophotomap. Vegetated areas have low coherence values, while urban and agricultural areas - high.

\section{Results}

As result of the DInSAR analysis, the differential interferogram was generated. The fringes visible on the interferogram could be used to estimate ground subsidence that occurred during the period 29.11.2015 - 23.12.2015, due to the phase differences are proportional to the terrain deformation. Each full range values change on the interferogram fringes represents the ground displacement in the line of sight direction by half the wavelength used by the SAR system (for Sentinel-1 data $-2,75 \mathrm{~cm}$ ). The obtained results were processed to represent deformations in the vertical direction (Fig.2). In the analysed period 45 subsidence troughs with depths of 1 to $10 \mathrm{~cm}$ were identified in the USCB area. The largest subsidence occurred in the municipality of Pawłowice (subsidence trough depth - 10 $\mathrm{cm}$, center of the trough $-49^{\circ} 58^{\prime} \mathrm{N} 18^{\circ} 43^{\prime} \mathrm{E}$ ), Marklowice (subsidence trough depth $-9 \mathrm{~cm}$, center of the trough $\left.-50^{\circ} 02^{\prime} \mathrm{N} 18^{\circ} 31^{\prime} \mathrm{E}\right)$ and Gierałtowice $\left(7,5 \mathrm{~cm}, 50^{\circ} 12^{\prime} \mathrm{N} 18^{\circ} 46^{\prime} \mathrm{E}\right)$. All subsidence troughs were detected on hard coal deposits areas, so they can be linked with mining activities. 


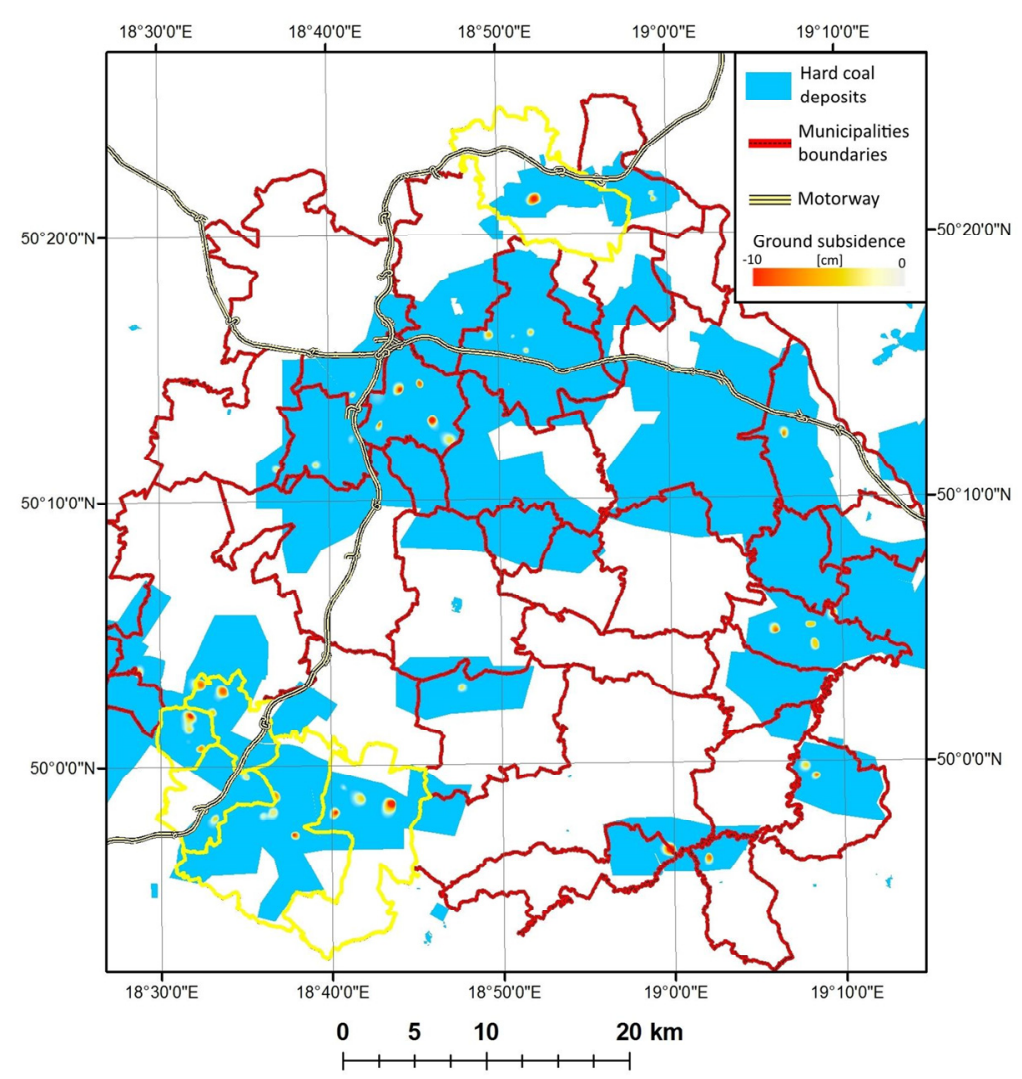

Fig.2. Map of ground subsidence that occurred between 29.11.2015 - 23.12.2015. Subsidence troughs were detected only on hard coal deposits areas.

\section{Examples of ground subsidence information use in GIS analysis}

\subsection{Choosing the optimal location for investment}

Geographical data are widely used in investment decisions making process. Appropriate compilation and visualization of this type of data is an important tool both at the stage of investment planning and its implementation. There are many factors that decide which investment plot will be optimal. Most important of them are: utilities infrastructure, intended use in the spatial development plan, accessibility of the transport network, geological and hydrological conditions, demography of the area, slope of the area, insolation, etc. Almost any kind of information about the property can prove invaluable in the context of the investment decision-making. It is therefore important to use a large collection of relevant data.

Historical information about the ground stability of the area, which in the target of the investment, will allow to better assess whether the given plot is risk and effort suitable. In addition, ongoing terrain subsidence monitoring during the implementation of the investment enables quick recognition and undertaking of activities minimizing the 
occurrence of damage to objects during their construction. However, it should be noted that the DInSAR method provides only information about subsidence that occurred in the past and does not provide any information whether this phenomenon will occur in the future.

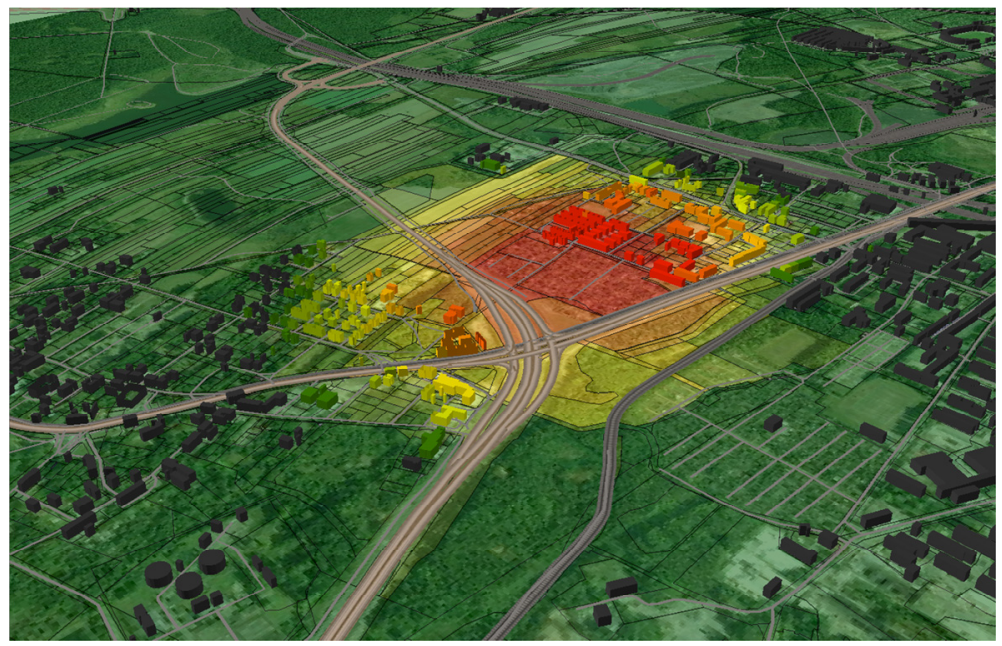

Fig.3. Mean values of ground subsidence within individual plots (29.11.2015 - 23.12.2015). Plots indicated on red are not suitable for investment.

In order to properly interpret the results, 5 thematic layers (orthophotomap, buildings map, roads and railway tracks map, boundaries of plots, ground subsidence information) were put together in order to indicate plots that are not suitable for investment (Fig.3). GIS analysis enabled to identify specific plots, buildings and fragments of roads and railway tracks under which the ground is unstable and the risk of mining damage occurrence is high (red colour). It is not recommended to build new buildings in the area located close to the intersection of two main roads, as the impact of underground mining is still high there.

\subsection{Designing highway routes}

Roads and railway tracks are susceptible to the destructive effects of ground deformation. These deformations are often the cause of cracking and damage of asphalt surfaces. This can significantly reduce or even prevent the use of routes. Vertical surface displacements information can be used to plan the course of new roads and railway tracks. Individual scenes of radar image cover large areas (even over $15000 \mathrm{~km}^{2}$ ), which allows to detect unstable areas in a wide spatial context. When planning a new road, it is necessary to take into consideration existing roads, railway tracks, building, land development, and many other information. In areas threatened by land subsidence it is also necessary to include this information in analysis. The largest threat to infrastructure was detected in the municipalities of Marklowice, Pawłowice and Świerklany (Fig.4). To predict the further development of this threat, information about the planned mining activity should be included in analysis. However, information about the current and past subsidence allows to state that the area is still unstable and exclude them while planning new routes. 


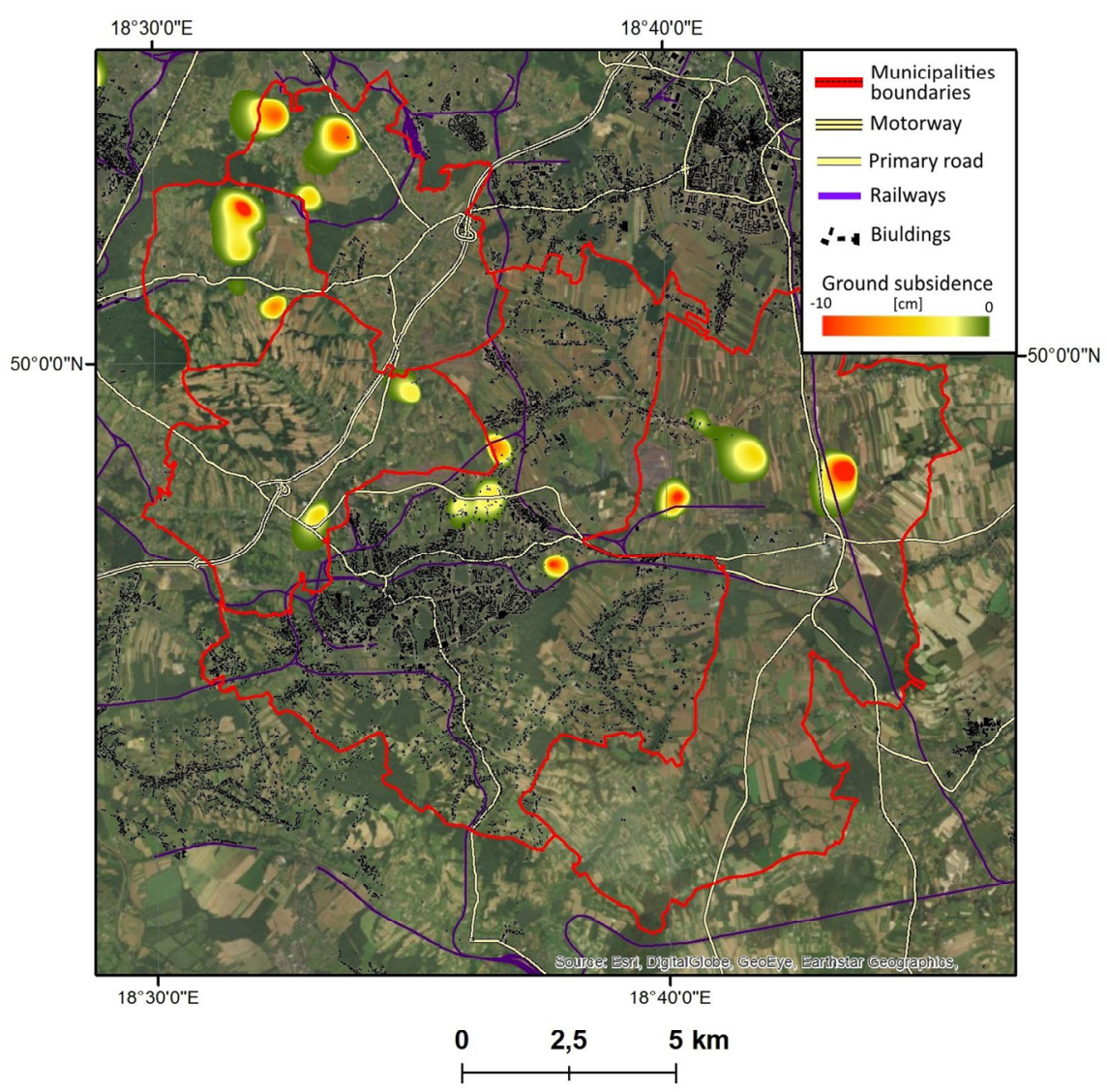

Fig. 4. Map of ground subsidence that occurred between 29.11.2015 - 23.12.2015. In many cases ground subsidence occurs in areas where roads and railways pass through. Such situations should be avoided in road planning.\#

\subsection{Assessment of mining activity impact on infrastructure damage}

Mining exploitation is often carried out under buildings and urban infrastructure. Continuous ground deformations caused by exploitation lead to infrastructure damage on the surface. Mining and construction analysis does not always allow to clearly determine whether the damage was caused by underground mining activity or other factors (such as construction defects of the building, surface vibrations). It is often stated in advance that if the facility is located in a mining area, then mining activity is the cause of the damage. On the other hand, the ground subsidence measurements is performed on a regular basis only by representatives of the mines and they are the owners of these results. In addition, the reliability of these measurements is often questioned by the owner of the damaged object. The lack of other alternative sources of information about ground subsidence causing mining damage is a significant problem in claiming for loss compensation. Satellite data is in this matter a reliable and independent source of information on terrain deformations. It can therefore be used in the process of assessing the cause of surface infrastructure damage.

Fig. 5 shows the following information layers combined: ground subsidence isolines, roads and buildings. The depth of the detected trough reaches $6 \mathrm{~cm}$. The trough covers the 
part of DK94 and DK88 roads, as well as the Family Garden Parks "Rekreacja", residential buildings between "Warszawska" and "Celna" streets. The area of the trough is $0.95 \mathrm{~km}^{2}$. In this area infrastructure damages have been observed for many years. The combination of several thematic layers (plots map, roads, buildings) can help to link the damages occurring on individual buildings and roads with the subsidence phenomenon caused by mining activities.

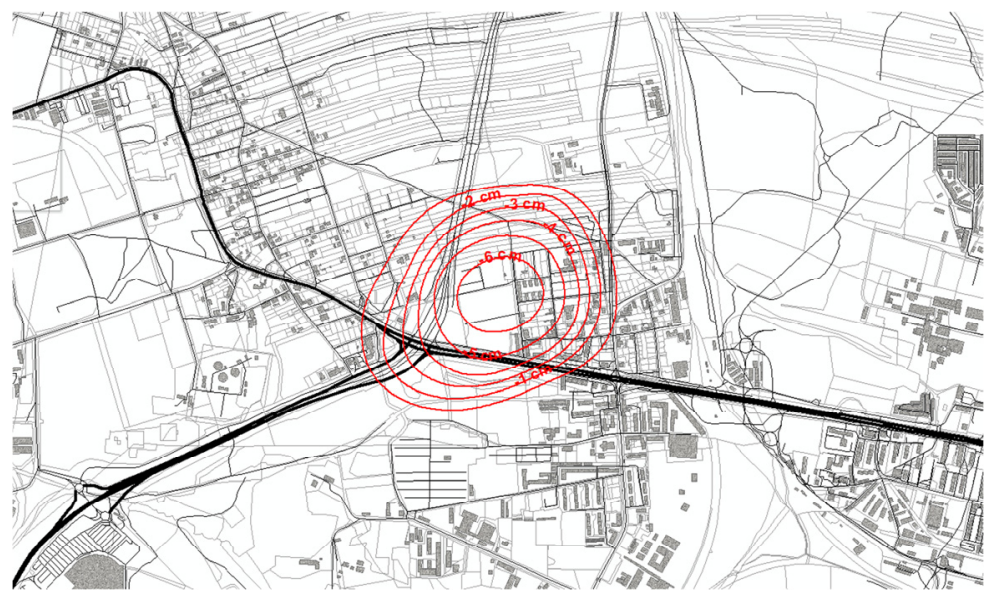

Fig. 5. Map of ground subsidence isolines that occurred between 29.11.2015 - 23.12.2015 in Bytom. Buildings located in the center of the subsidence trough were damaged as a result of underground exploitation in this area.\#

\subsection{Spatial planning}

The local spatial development plan is the basic document at the local level containing urban planning guidelines for the municipality. This document specifies the intended land use of areas. In order to prepare this document, natural hazards, such as flood occurrence, are taken into account. This prohibits constructions of building on endangered areas. Incorporation of ground subsidence information into analysis would complement the analysis with another thematic layer concerning threats. Indication of the areas on which the subsidence troughs still occurs will enable more conscious determination of areas that should be excluded from development. In addition, such information will be an additional source in assigning appropriate mining category to the given area.

The areas indicated on Fig. 2 as being threatened with subsidence should be used for agricultural production or recreation. Since these areas are still unstable, they should not be designated for development, and for the construction of large objects. Possibly threatened areas should be designated for reclamation to minimize and mitigate the environmental effects of mining activity.

\section{Conclusions}

The use of many layers of reliable information in the GIS analysis will allow to minimize the risk associated with making inappropriate planning decisions. Such analysis is cheap, fast and accurate. Analysis based on complete data is crucial especially for local government units. Ground subsidence information can be an important element in GIS 
analysis on areas where mining activities are performed or were performed in past. Including this layer in analysis will help to make better decisions in such aspects as:

- security - by excluding areas threatened with ground subsidence from planning new buildings, or in case of detecting the subsidence threat take an appropriate action aimed at infrastructure securing,

- economical - minimization of the costs of mining damage removing by selecting the appropriate area for investment,

- determining the cause and effect relationship between the mining activity and the resulting damage.

Detection of the areas where ground subsidence occurred is sufficient to conclude that these areas are still unstable. This threat must be taken into account in spatial planning.

This work was financed by the statutory research funds of the Department of Geoinformatics and Applied Computer Science AGH No. 11.11.140.613

\section{References}

1. Bilans zasobów złóż kopalin w Polsce wg stanu na 31.12.2013 r., Panśtwowy Instytut Geologiczny (2014)

2. Program Ochrony Środowiska dla Województwa Śląskiego do roku 2019 z uwzględnieniem perspektywy do roku 2024 (2015)

3. M. Crosetto et al., Subsidence monitoring using SAR interferometry: reduction of the atmospheric effects using stochastic filtering, Geophysical Research Letters, 29(9), 2629 (2002)

4. T. Strozzi, U. Wegmiiller, L. Tosl, G. Bitelli, V. Spreckels, Land Subsidence Monitoring with Differental SAR Interferomerty, Photogrammetric Engineering \& Remote Sensing, 67, 1261-1270 (2001)

5. H. Duzgun, N. Demirel, Remote Sensing of the Mine Environment, CRC Press, (2011)

6. Z. Perski, Applicability of ERS-1 and ERS-2 InSAR for land subsidence monitoring in the Silesian coal mining region, Poland, Int. Arch. Photogramm. Remote Sens., 32, 555558 (1998)

7. E. Pilecka, D. Szwarkowski, An application of the ground laser scanning to recognise terrain surface deformation over a shallowly located underground excavation, E3S Web of Conference, Vol. 24, 1-8 (2017)

8. R. P. Gupta, Remote Sensing Geology, Springer-Verlag Berlin Heidelberg New York, (2003)

9. R. F. Hanssen, Radar Interferometry. Data Interpretation and Error Analysis, Kluwer Academic Publishers (2001).

10. A. Ferretti, F. Novali, R. Bürgmann, G. Hilley, C. Prati, InSAR Permanent Scatterer Anaysis Reveals Ups and Downs in San Francisco Bay Area, Eos, 85, No. 34, 317-324 (2004)

11. P. Prats-Iraola et al., Sentinel-1 Assessment of the Interferometric Wide-Swath Mode. 1-4. 10.1109/IGARSS.2015.7327018 (2015)

12. A. Ferretti, A. Monti-Guarnieri, C. Prati, F. Rocca, InSAR Principles: Guidelines for SAR Interferometry Processing and Interpretation, ESA Publications, TM-19 (2007) 